\title{
A STUDY ON OVERALL PERFORMANCE OF THE NURSES ON FACTORS INFLUENCING EMOTIONAL LABOUR BY USING THE NEURAL NETWORK (NN) METHOD IN PRIVATE HOSPITALS IN CHENNAI
}

\author{
K. Rohini \\ Research Scholar, PG and Research Department of Business Administration, \\ J.J. College of Arts and Science College (Autonomous), \\ (Affiliated to Bharathidasan University), Pudukkottai, Tamilnadu, India \\ Dr. S. Parithi \\ Assistant Professor, PG and Research Department of Business Administration, \\ J.J. College of Arts and Science College (Autonomous), \\ (Affiliated to Bharathidasan University), Pudukkottai, Tamilnadu, India
}

\begin{abstract}
With the expanding complexities both in business and human conduct, made the requirement for individuals with high IQ as well as individuals with high EQ more. In the present time where the trademark "Client is the King" wins in each organization the emotionally imbalanced may think that it's difficult to accomplish theirobjectives. The manner in which an individual feelsinfluences the manner in which he carries on and the manner in which he acts and additionally influences the people around him. Number of research has been led on this problem that isbegging to be addressed both in developed and developing nations covering the different parts of feelings at working environment, relationship of Emotional Labour (EL)qualities, for example, discernment, control, use and comprehension of feelings, with physical and mental wellbeing to decide the benefits of the information and use of Emotional Labour. In developing nation particularly India, there is shortage of writing concentrating on this significant part of Emotional Labour. So a need emerges to consider this idea in Hospital Sector which is the foundation of curative care and liable for the general development of the country at a huge.
\end{abstract}


A Study on Overall Performance of the Nurses on Factors Influencing Emotional Labour by Using the Neural Network (NN) Method in Private Hospitals in Chennai

Key Words: Emotional Labour, Performance, Hospitals, NN Method

Cite this Article: K. Rohini and S. Parithi, A Study on Overall Performance of the Nurses on Factors Influencing Emotional Labour by Using the Neural Network (NN) Method in Private Hospitals in Chennai, International Journal of Management, 11(12), 2020, pp 3365-3374.

http://iaeme.com/Home/issue/IJM?Volume=11\&Issue $=12$

\section{INTRODUCTION}

Emotional labour is seen as the person's capacity to perceive and comprehend one's feelings and aptitudes that an individual uses so as to deal with themselves as well as other people. Scholarly aptitudes and specialized capability is not sufficient to make progress in one's activity obligations, however it is basic for an individual to practice self-administration, restraint and successful relational connections that would contribute in accomplishing the ideal objectives and targets. Well-handled emotional labour process likewise empowers Nurses to actualize compelling abilities to give their best to the Hospital and Nurses. The idea of emotional labour contributes in the improvement of the aptitudes and capacities of the people in a wide extending way that they would absolutely have the optionto adequately render a usable commitment at the working environment. Emotional labour includes a mix of abilities, which permit an individual to know about, to comprehend, to be in charge of his own feelings and display the required emotions. It is essential to perceive and comprehend the feelings of others and to utilize the information and abilities to cultivate their prosperity just as the achievement of others. People with an exceptionally ability to handle emotional labour are increasingly effective at their work environment, the primary explanation being that they can comprehend their feelings ad the purposes for their direct and conduct attributes.

Nurses form a significant part in any Hospital. Nurse's presentation and dealing with patient assumes a significant job in helping the hospital since they are face of the hospital. Patients regularly judge and provide feedback to a hospital primarily based on the conduct and disposition of itsemployees. Administration part increases an upper hand through its and their predominant presentation. So as to endure and to hold a serious edge, hospitals put consistent focus on Nurses to perform well.

The healthcare segment is one of the premier divisions in any nation that helps the nation to grow. Contrasted with the most recent couple of decades, new hospitals are developing, step by step along these lines are expanding rivalry among the hospitals, driving the current hospitals to re-evaluate their current procedures, strategies, frameworks, structures and so forth. Increasing feasible competitive advantage can be achieved through human capital, since one of the most significant key assets in any organization is the human asset. Right now, the organization must consider the emotion component equipped in making progress through the individuals. Numerous researchers have confirmed that hospitals performs better by having emotionally savvy at the work environment. Execution is connected to factors viz, worker turnover, consumer loyalty, reliability, efficiency and benefit. Organizations have gotten significantly more requesting just as intricate and vaguework environments. Emotional labour includes a mix of capabilities which permit an individual to know about, to comprehend, and to be in charge of their own feelings, to perceive and comprehend the feelings of others, and to utilize this information to cultivate their prosperity and the achievement of others.

\section{RELATED EMPIRICAL STUDIES}

Outrage is a typical response and experienced in practically regular daily existence circumstances, e.g., at home, school, in broad daylight place, work environment, interpersonal 
relationships, and so on and is a sound human feeling. In its sound structure, outrage impartsan admonition sign to the mind that something isn't right and furnishes the body with vitality as to alter the circumstance. The special versatile capacity of outrage is assembly ofvitality to make a move (Thomas, 2002).

It can cause a person to enjoy antisocial exercises, for example, savagery, harming property, harming others genuinely or verbally and so on. Over all it 'annihilates interpersonal relationships, influences conjugal relationships, causes psychological instability, hinders judgment, and results in savage violations, street rage, dangerous driving, and it can transform into other upsetting emotions, for example, antagonistic vibe, disdain, harshness, scorn and other wellbeing problems. (Deffenbacher, 1992; Deffenbacher et al., 2002; Deffenbacher et al. 2003: Saini, 2009). At the point when every one of these emotions are predominant in any work environment, the workplace will endure - thus bringing about less creation.

Adaptability is an undefined build that is indicated to be appropriate in a scope of circumstances. It can likewise be seen from various points of view (Van Dam, 2013).

Stokes et al. (2010) explained that adaptability in the working environment has been conceptualized and researched as a result, for example, errand or employment execution, versatile expertize, as methodology determination or as a steady individual distinction build and so on. They further contend that while each examination adds to our understanding of working environment adaptability from numerous points of view in this manner explaining further. Pulakos et al. (2000) expansive meaning of versatile execution was changing conduct to satisfy the needs of the earth, occasion, or new circumstance.

Ployhart and Bliese (2006) model assisted with understanding individual contrasts with regards to adaptability. They further presented that the individual contrasts add to parts of job performance which can affect the undertaking, logical, and counterproductive work conduct. This hypothesis explains adaptability as an indicator as far as different KSAs . Anyway, this hypothesis doesn't consider versatile performance as a result. Explainingversatile performance as a foundation is significant for and discovering the helpfulness of job performance models which can be utilized by experts at the cutting edge of the evolving working environment.

Gohm, Corser and Dalsky (2005), learned about Emotional labour under Stress - regardless of whether it was valuable, pointless or insignificant. This examination among 158 respondents analyzed the relationship between emotional labour (feeling - important capacities) and stress (sentiments of failure to control life occasions), thinking about character (self - impression of the Meta - emotional quality of lucidity, madness and consideration) as a directing variable. Results recommended that emotional labour is conceivably useful in decreasing stress for certain people, yet superfluous or insignificant for other people. They featured the outcomes among the exceptionally stressed, extreme however befuddled members specifically in light of the fact that they have normal emotional Labour, yet don't seem to utilize it, apparently on the grounds that they need trust in their emotional capacity.

Kumar and Rooprai (2009) directed an investigation to break down if emotional labour is an indicator in overseeing stress and nervousness. Emotional labour Scale, Stress Inventory and General Anxiety test were utilized for the estimation of the considerable number of factors. Emotions have an indispensable influence in overseeing stress and tension at work environment. It featured the requirement for assessment of the relationship of emotional labour as a general idea to the management of stress.

Corser et al (2005) inspected the relationship between emotional labour (feeling significant capacities) and stress (sentiments of powerlessness to control life occasions), thinking about character (self-impression of the meta-feeling characteristics of lucidity, force, and consideration) as a directing variable. Emotional labour is conceivably useful in lessening stress for certain people, however pointless or superfluous for other people. 
A Study on Overall Performance of the Nurses on Factors Influencing Emotional Labour by Using the Neural Network (NN) Method in Private Hospitals in Chennai

The intrapersonal competency includes being in line with self-regard and stress management aptitudes (Nelson and Low, 2011). The creators portrayed "self-crushing and "selfruinous practices" that can affect a person's psychological and physical wellbeing, yet the soundness of the organization. They likewise note that turning out to be self-mindful of a few between related emotions that contain stress and self-regard are significant when attempting to improve this competency.

Nelson and Low's EI develop are abbreviated into four capabilities: (a) self-management abilities; (b) individual administration aptitudes (c) intrapersonal abilities (d) interpersonal aptitudes. The ESAP gives the establishment to the study instrument that will be utilized right now. Some portion of the ESAP utilizes the emotional learning framework (ELS), which is a five-advance procedure to help with adapting to stressful encounters. Be that as it may, for the reasons for this investigation, the ELS won't be utilized since it is a post appraisal work out. This instrument was consolidated utilizing Nelson and Low's ESAP An arrangement to all the more precisely mirror the working conditions reliable with the literature investigate discoveries as identified with IT professionals' have to create interpersonal and intrapersonal abilities (Gillard 2009; Tang and Mu-Shang, 2008).

Tang and Mu-Shang's (2008) study saw IT professionals as insufficient in the EI competency regions of interpersonal and intrapersonal abilities. They declared that an intelligence expertise under the interpersonal competency was inadequate in their discoveries and gave a knowledge to the possibility that IT professionals experience issues being agreeable around their friends. Another finding demonstrated that stress management, an EI intelligence expertise of the intrapersonal competency, was lower among IT professionals, showing their absence of stress adapting abilities to expanded outstanding tasks at hand. They recommended, for additional examination, to imitate their investigation on progressively experienced IT professionals since their example of IT professionals were college understudies took a crack at data innovation disciplines at a university.

\section{PROBLEM STATEMENT}

There has been considerable proof demonstrating that being emotionally shrewd can assist people with exceeding expectations through life advances beginning from school to college, and later into the working place. Emotional labour is viewed as an important aptitude that encourages individual to oversee and adapt to the requesting idea of the corporate. Various investigations have just settled the constructive connection between ' emotional labour and execution, referring to reasons, for example, emotionally intelligent have better relational and intrapersonal aptitudes, are progressively versatile, and are better at overseeing pressure. In addition, emotionally savvy employees are progressively fruitful in carrying on with their work life and in this way, can learn and perform well in their activity.

Notwithstanding that, being emotionally shrewd not only help Nurses to learn better but it also determines their career success, especially for those who want to embark into a profession that requires high level of emotion related competence. Managing patients is high in emotional work. Emotional labour alludes to "the degree to which a Nurse should communicate proper feelings to exceed expectations in their activity", which is basically fundamental to being emotionally astute. Hence, there is a need for those who aspire to become Nurses to possessthe skills of emotional Labour. This study aims to find out the level of emotional labour among the Nurses in the selected private hospitals in Chennai and to investigate its influence on their job involvement and performance. 


\section{OBJECTIVE OF THE STUDY}

A study on overall performance of the nurses on factors influencing emotional labour by using the Neural Network (NN) method in private hospitals in Chennai

\section{RESEARCH METHODOLOGY}

Primary and Secondary Data collection methods have been followed in the research study. Under the primary data collection method structured questionnaire has been used to collect data from the sample respondents. The questionnaire consists of questions which explain about the demography of the respondents like age, marital status, educational qualification, Designation, experience, etc., and all the other questions related to the dimensions taken for the study. After pre testing with 50 Nurses appropriate modifications were made in the questionnaire. Nominal and Ordinal scaling has been used to find out the Socio demographic factors, Factors influencing Emotional Labour, Emotional Labour components, Job Involvement and Nurse performance such as,

- Strongly Agree

- Agree

- Neutral

- Disagree

- Strongly Disagree

Population of the present study consists of the Nurses of the selected private hospitals in Chennai. As the population is very large, descriptive research design was adopted and Purposive sample method has been used in the present study. The Purposive sampling technique was used for choosing the respondents for thepresent examination. This strategy is utilized in expressive research where the analyst is keen on getting an economical estimate of the data and truth. The purposive sampling technique, likewise called judgment sampling, is the intentional decision of a source because of the characteristics the witness has. It is a non-arbitrary technique that doesn't require basichypotheses or a set number of witnesses. The fundamental objective of purposive sampling is to concentrate on specific qualities of a populace that are of intrigue, which will best empowerus to respond to our exploration questions. It is the probabilistic or arbitrary sampling that is utilized to guarantee the generalizability of discoveries by limiting the potential for inclinationin determination and to control for the potential impact of known and obscure confounders.

Sample size implies the amount of things to be looked over the universe to build up a sample. It has a quick bearing on how accurate the revelations are regarding the real characteristics in the people. Consequently, choosing a fitting sample size for this assessment was seen as a chief criticalness. The total proposed sample from the selected hospitals is obtained finally for the study. Therefore the proposed sample size accounts to 100 from the selected four hospitals for the study.

\section{ANALYSIS OF OVERALL PERFORMANCE OF THE NURSES ON FACTORS INFLUENCING EMOTIONAL LABOUR BY USING THE NEURAL NETWORK (NN) METHOD}

The Neural Network architecture, used in this study, is a multilayer feed forward network using SPSS 20. The architecture which provides the best fit for the data is the network with three hidden layers and an output layer. The learning and momentum parameters are 0.6 and 0.9 respectively and error convergence falls below 0.01 Percent. Tan sigmoid is the activation 
A Study on Overall Performance of the Nurses on Factors Influencing Emotional Labour by Using the Neural Network (NN) Method in Private Hospitals in Chennai

function chosen for the hidden layers, and the pure linear function is used to get the output layer which is the real time values. The architecture which provides the best fit for the data is the network with seven input layers, thirty covariate variables and one hidden layers and one output layer, as shown in figure 1.

The model used in this work is the Feed Forward Multilayer perception, using the Back Propagation Algorithm. Where (4-3-1)7-Input layers

- 30-Covariates layers

- 1-Hidden layers

- 1-Output layer

All inputs are analyzed in the experimental validation part, with appropriate output results by the illustration of graphs so that the influences of the parameters of tensile strength are taken into consideration. The network information is presented in the table. The validation of the estimated NN and Experimental value illustrations is shown in Figure.

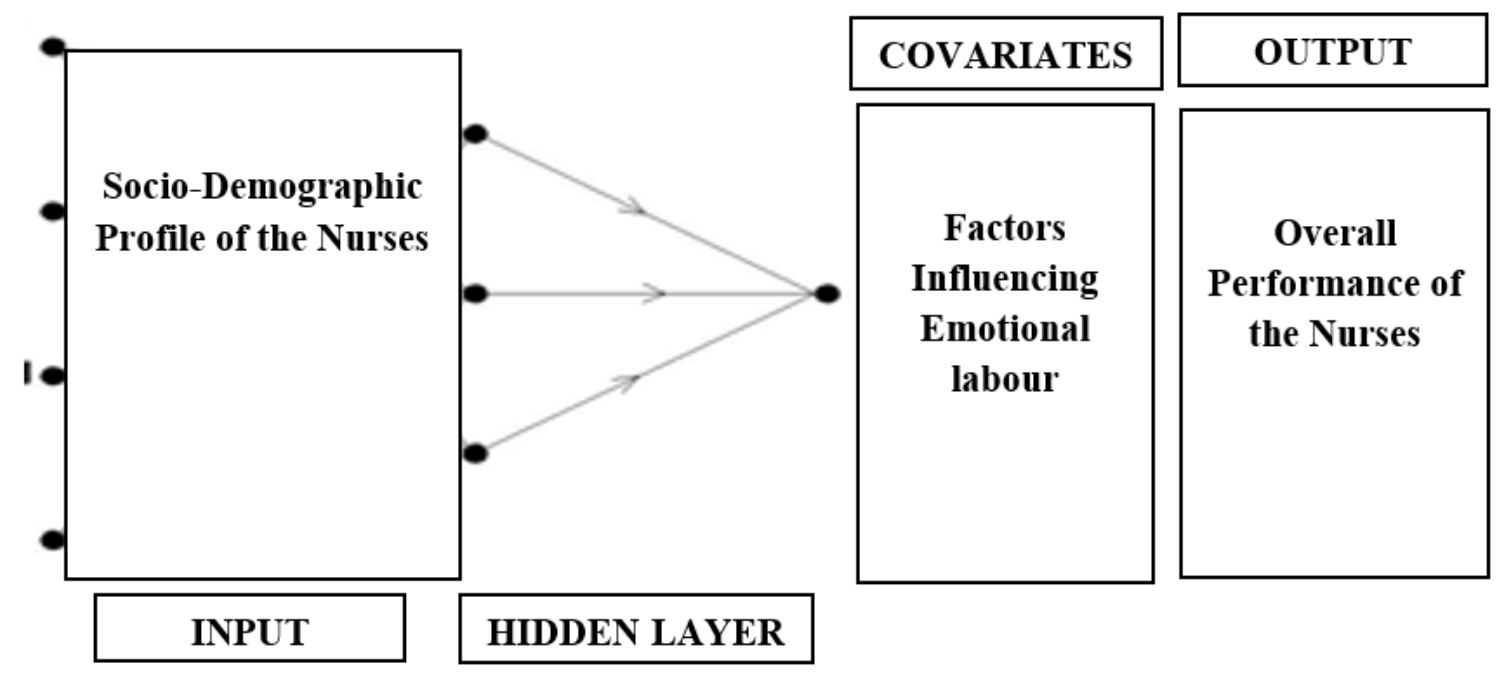

Figure 1 Basic Neuron Model for overall performance of the Nurses on factors influencing emotional Labour

Table 2 Model Summary for Neural Network Model for factors influencing emotional Labour

\begin{tabular}{|l|l|c|}
\hline \multirow{4}{*}{ Training } & Sum of Squares Error & 81.739 \\
\cline { 2 - 3 } & Relative Error & .270 \\
\cline { 2 - 3 } & Stopping Rule Used & 1 consecutive step(s) with no decrease in error ${ }^{\mathrm{a}}$ \\
\cline { 2 - 3 } & Training Time & $0: 00: 01.69$ \\
\hline \multirow{2}{*}{ Testing } & Sum of Squares Error & 49.618 \\
\cline { 2 - 3 } & Relative Error & .376 \\
\hline \multicolumn{2}{|l|}{ Dependent Variable: Overall performance } \\
\hline \multicolumn{2}{|l|}{ a. Error computations are based on the testing sample. }
\end{tabular}

Source: Output generated from SPSS 20 
Table 3 Neural Network Model for overall performance of the Nurses on factors influencing emotional Labour

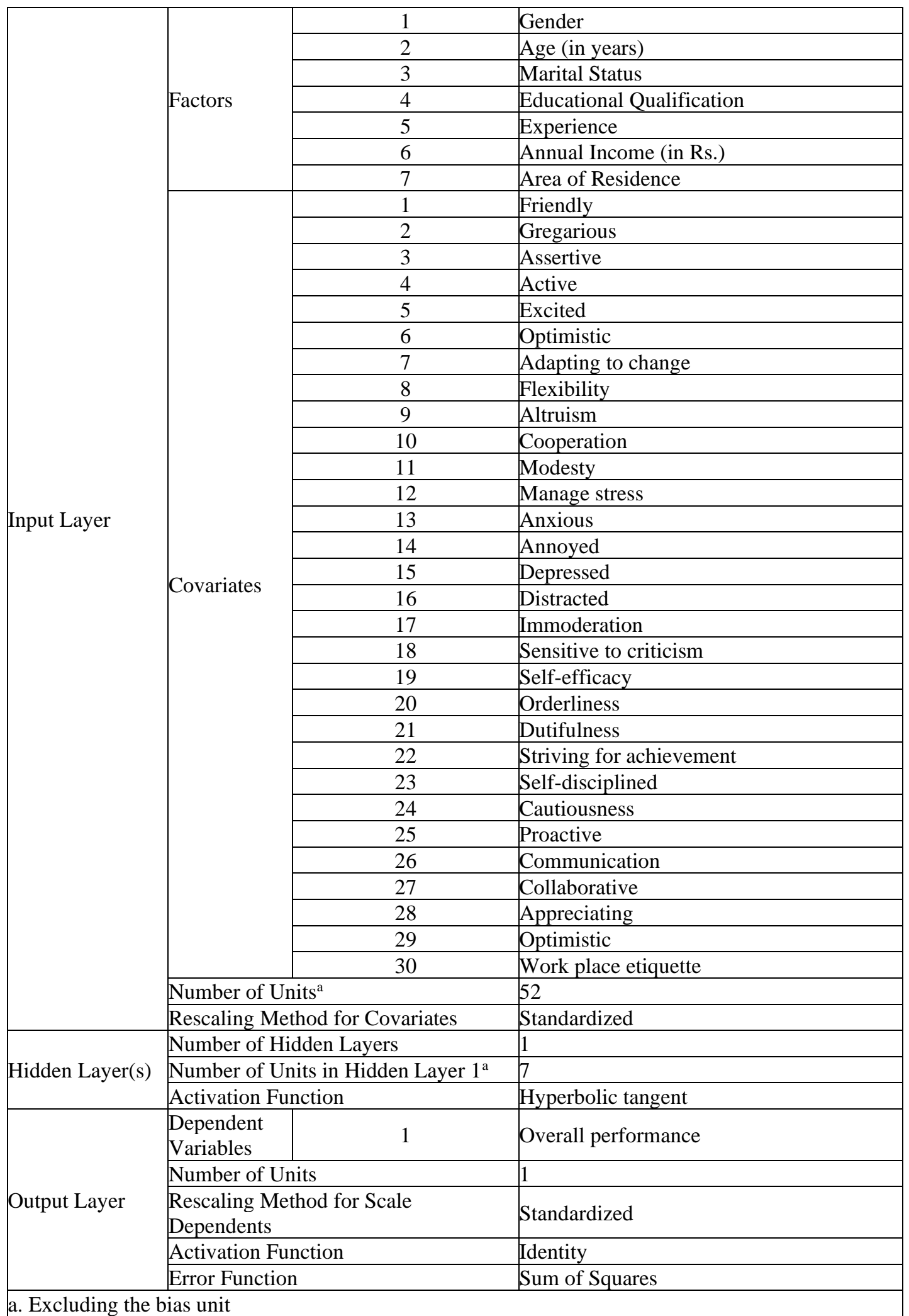

Source: Output generated form SPSS 20.

The factors of the factors influencing emotional labour model parameters are modelled by using the Neural Network Method. The parameters are optimized so as to determine the set of 
A Study on Overall Performance of the Nurses on Factors Influencing Emotional Labour by Using the Neural Network (NN) Method in Private Hospitals in Chennai

parameters, which will influence the increase in the Overall performance of Nurses on factors influencing emotional labour by using Neural Networks Architecture and network information.

Table 4 Independent Variable importance for Neural Network Model for the overall performance of the Nurses on factors influencing emotional Labour

\begin{tabular}{|l|c|c|}
\hline \multicolumn{1}{|c|}{ Independent Variable Importance } & Importance & Normalized Importance \\
\hline Gender & .009 & $3.8 \%$ \\
\hline Age (in years) & .015 & $6.7 \%$ \\
\hline Marital Status & .007 & $3.1 \%$ \\
\hline Educational Qualification & .020 & $8.9 \%$ \\
\hline Experience & .016 & $7.2 \%$ \\
\hline Annual Income (in Rs.) & .022 & $9.5 \%$ \\
\hline Area of Residence & .021 & $9.1 \%$ \\
\hline Friendly & .020 & $8.6 \%$ \\
\hline Gregarious & .017 & $7.5 \%$ \\
\hline Assertive & .011 & $4.7 \%$ \\
\hline Active & .025 & $10.9 \%$ \\
\hline Excited & .027 & $11.6 \%$ \\
\hline Optimistic & .229 & $100.0 \%$ \\
\hline Adapting to change & .025 & $11.0 \%$ \\
\hline Flexibility & .025 & $10.8 \%$ \\
\hline Altruism & .027 & $11.7 \%$ \\
\hline Cooperation & .020 & $8.5 \%$ \\
\hline Modesty & .035 & $15.3 \%$ \\
\hline Manage stress & .019 & $8.1 \%$ \\
\hline Anxious & .034 & $14.8 \%$ \\
\hline Annoyed & .023 & $9.9 \%$ \\
\hline Depressed & .012 & $5.1 \%$ \\
\hline Distracted & .028 & $12.0 \%$ \\
\hline Immoderation & .019 & $8.1 \%$ \\
\hline Sensitive to criticism & .022 & $9.7 \%$ \\
\hline Self-efficacy & .016 & $6.9 \%$ \\
\hline Orderliness & .030 & $13.0 \%$ \\
\hline Dutifulness & .023 & $10.1 \%$ \\
\hline Striving for achievement & .031 & $13.5 \%$ \\
\hline Self-disciplined & .033 & $14.4 \%$ \\
\hline Cautiousness & .013 & $5.9 \%$ \\
\hline Proactive & .025 & $10.9 \%$ \\
\hline Communication & .017 & $7.2 \%$ \\
\hline Collaborative & .023 & $9.9 \%$ \\
\hline Appreciating & .010 & $4.4 \%$ \\
\hline Optimistic & .034 & $15.0 \%$ \\
\hline Work place etiquette & .018 & $7.7 \%$ \\
\hline Source Output generat & \\
\hline & & \\
\hline
\end{tabular}

Source: Output generated from SPSS 21 


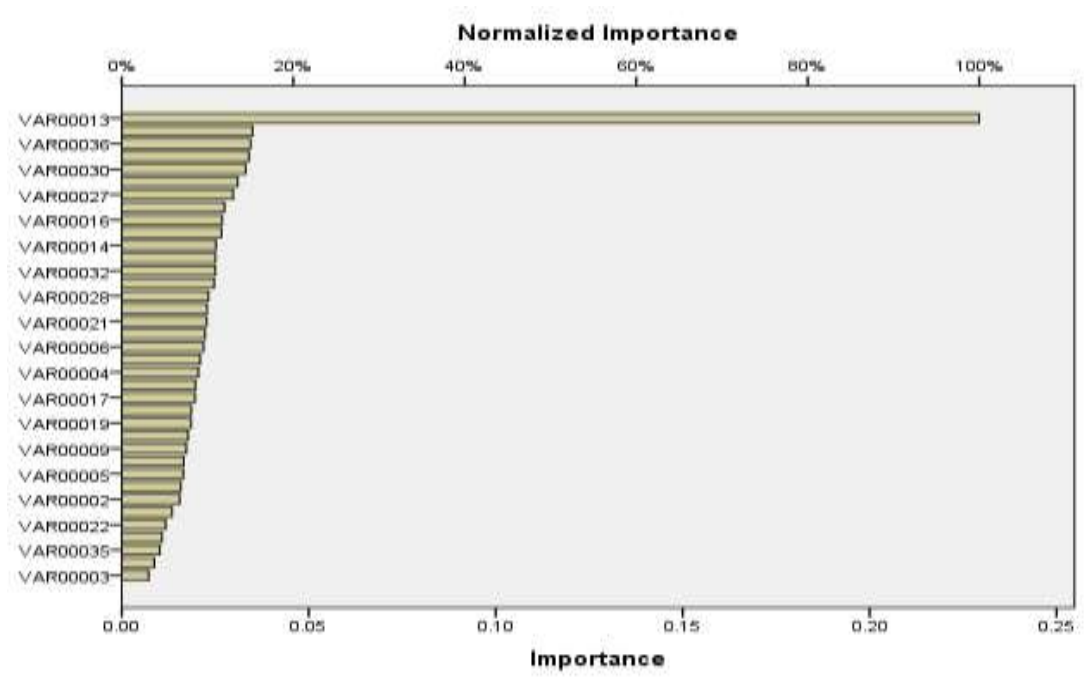

Figure 2 Normalized importance for the overall performance of the Nurses on factors influencing emotional Labour

The table and diagram shows the factors influencing emotional labour in respect of "Optimistic" is contribute more towards the output of overall performance of the Nurses.

\section{FINDINGS}

The outcome of neural network analysis infers the complex nonlinear relationships between dependent and independent variables of the factors influencing emotional labour dimension and attempts to detect all possible interactions between the attributes under the perception towards emotional labour in the selected private hospitals considered for the study. The most interacting factor is identified as 'Optimistic' under the sub dimension of Factors influencing Emotional Labour, "General Mood". The respondents' opinion on emotional labour and their impact on performance is perceived more interactive with the factor positive thinking emotion among all other statements of opinion. Hence among all other attributes under factors influencing emotional Labour, the above said statement is statistically significant and thus identified as the most interactive variable.

\section{SUGGESTIONS AND CONCLUSION}

There is need for motivation programmes which can also be incorporated in the training programmes that induces the employees in providing innovative solutions and better decision making. Thus their emotional labour, increases. When any organization invests more amounts of energy towards the organizing the components which influence the EI most as a light emission then the quality assistance factors would determine as a constituent spectrum of colours which will additionally expand the benefits and efficiency of Hospitals. However, this procedure of actualizing the Emotional labour in the Hospitals isn't one stage and one go process. It is a type of hierarchical change this ought to be operationalize at an agonizingly slow change. Organizations must identify the critical competencies associated with emotional Labour that are appropriate for the organization and develop those competencies among the employees. This will lead to enhanced organizational effectiveness. Similar initiatives can be carried out for job involvement also. Organizations must actively seek opportunities to empower their employees. Empowered managers lead to empowered employees. Empowered employees have been found to take quick decisions and respond rapidly to the needs of stakeholders. 
A Study on Overall Performance of the Nurses on Factors Influencing Emotional Labour by Using the Neural Network (NN) Method in Private Hospitals in Chennai

\section{REFERENCES}

[1] Deffenbacher, J. L., Lynch, R. S., Oetting, E. R., \& Swaim, R. C. (2002). The Driving Anger Expression Inventory: A measure of how people express their anger on the road. Behaviour Research and Therapy, 40(6), 717-737.

[2] Deffenbacher, J. L., White, G. S., \& Lynch, R. S. (2004). Evaluation of Two New Scales Assessing Driving Anger: The Driving Anger Expression Inventory and the Driver's Angry Thoughts Questionnaire. Journal of Psychopathology and Behavioral Assessment, 26(2), 87-99.

[3] Dulewicz, V. (2000), "Emotional intelligence: the key to future successful corporate leadership?", Journal of General Management, Vol. 25, pp. 1-14.

[4] Casanovas-Vilar I, van Dam J (2013) Conservatism and Adaptability during Squirrel

Radiation: What Is Mandible Shape Telling Us?

https://journals.plos.org/plosone/article?id=10.1371/journal.pone.0061298

[5] Pulakos, E.D., Arad, S., Donovan, M.A., Plamondon, K.E., 2000. Adaptability in the workplace: development of a taxonomy of adaptive performance. J. Appl. Psychol. 85 (4), 612.

[6] Corser, C., \& Dalsky, J., (2005). Emotional Intelligence under stress: Useful, unnecessary, or irrelevant. Personality and Individual Differences, Vol. 39, Issue 6, Pages 1017-1028.

[7] Nelson, D. B. \& Low, G. R. (2011). Emotional intelligence: Achieving academic and career excellence (2nd ed.). Upper Saddle River, NJ: Pearson Education.

[8] Gillard, S. (2009). Soft skills and technical expertise of effective project managers. Issues in informing science \& information technology, 6, 723-729. Retrieved from http://iisit.org/Vol6/IISITv6p723-729Gillard599.pdf

[9] Tang, V., \& Mu-Shang, Y. (2008). Emotional intelligence characteristics of IT professionals in Taiwan. IT in Medicine and Education, 2008. ITME 2008. IEEE International Symposium (pp. 108-113). doi: 10.1109/ITME.2008.4743832.

[10] Trong Tuan, L. (2013). Emotional intelligence as the departure of the path to corporate governance. Corporate Governance: The international journal of business in society, 13(2), 148168. https://doi.org/10.1108/14720701311316634.

[11] Winter, K.A. and Kuiper, N.A. (1997), "Individual differences in the experience of emotions",Clinical Psychology Review, Vol. 17, pp. 791-821.

[12] Wong, C.S., Law, K.S., \& Wong, P.M. (2004). Development and validation of a forced choice emotional intelligence for Chinese respondents in Hong Kong. Asia Pacific Journal of Management, 21(4), 535-559.

[13] Zehndorfer Elesa. (2014) Leadership: A Critical Introduction: Published by Taylor \& Francis Ltd, United Kingdom (2014).

[14] Zeidner, M., \& Matthews, G. (2017). Emotional intelligence in gifted students. Gifted Education International, 33(2), 163-182. 